\title{
Proteomic profiling of the hypothalamus in a mouse model of cancer-induced anorexia-cachexia
}

\author{
R Ihnatko*, ${ }^{\star}$, Post $^{1}$ and A Blomqvist ${ }^{*}, 1$ \\ ${ }^{1}$ Department of Clinical and Experimental Medicine, Division of Cell Biology, Faculty of Health Sciences, Linköping University, \\ Linköping, S-581 85, Sweden
}

Background: Anorexia-cachexia is a common and severe cancer-related complication but the underlying mechanisms are largely unknown. Here, using a mouse model for tumour-induced anorexia-cachexia, we screened for proteins that are differentially expressed in the hypothalamus, the brain's metabolic control centre.

Methods: The hypothalamus of tumour-bearing mice with implanted methylcholanthrene-induced sarcoma (MCG 101) displaying anorexia and their sham-implanted pair-fed or free-fed littermates was examined using two-dimensional electrophoresis (2-DE)-based comparative proteomics. Differentially expressed proteins were identified by liquid chromatography-tandem mass spectrometry.

Results: The 2-DE data showed an increased expression of dynamin 1, hexokinase, pyruvate carboxylase, oxoglutarate dehydrogenase, and $\mathrm{N}$-ethylmaleimide-sensitive factor in tumour-bearing mice, whereas heat-shock $70 \mathrm{kDa}$ cognate protein, selenium-binding protein 1, and guanine nucleotide-binding protein $\mathrm{G} \alpha_{0}$ were downregulated. The expression of several of the identified proteins was similarly altered also in the caloric-restricted pair-fed mice, suggesting an involvement of these proteins in brain metabolic adaptation to restricted nutrient availability. However, the expression of dynamin 1, which is required for receptor internalisation, and of hexokinase, and pyruvate carboxylase were specifically changed in tumour-bearing mice with anorexia.

Conclusion: The identified differentially expressed proteins may be new candidate molecules involved in the pathophysiology of tumour-induced anorexia-cachexia.

The anorexia-cachexia syndrome is one of the most common complications to cancer, and is characterised by loss of desire to eat, progressive wasting of adipose and muscle tissue with loss of body weight, poor performance status, and subsequent death. Key differences between the anorexia-cachexia syndrome and starvation due to food depletion are the equal degradation of fat and skeletal muscle during anorexia-cachexia and increased energy expenditure despite the reduced food intake (Body, 1999; Bosaeus et al, 2001). The lack of functional feedback between energy intake and energy expenditure in the anorexia-cachexia syndrome, which during normal starvation increases appetite and lowers energy loss, suggests an impaired function of the central energy homoeostatic centre in the brain. Accumulating evidence suggest a multifactorial nature of the anorexia-cachexia syndrome with deregulation of several physiological and biochemical systems (Tisdale, 2009). For example, in a murine cancer model (MCG 101), the role of innate immune signalling mediated by myeloid cells has been demonstrated for the development of anorexia (Ruud et al, 2013b), as well as the involvement of prostaglandins particularly those derived from cyclooxygenase-1 (Ruud et al, 2013a). Changes in expression of guanine nucleotide-binding proteins, which are involved in G-protein-coupled receptor signalling, have been shown in adipocytes of mice bearing MAC16 tumours as well as in a patient with cancer-associated weight loss (Islam-Ali et al, 2001). 
A decrease in glucose utilisation by the brain and several other tissues has been detected in tumour-bearing animals along with increased use of lactate and 3-hydroxybutyrate, which can stimulate pyruvate carboxylation, suggesting that ketone bodies may be utilised as a metabolic fuel during the cancer-bearing state (Siess, 1985; Mulligan and Tisdale, 1991).

It is well established that the hypothalamus is the main regulatory centre of the autonomic nervous system, controlling a number of body functions, including feeding behaviour and energy metabolism (Toni et al, 2004). A disturbance of this sensitive regulatory system may lead to a corresponding pathological condition. Studies in animal models of cancer-induced anorexiacachexia have demonstrated immediate-early gene expression in nuclei in the hypothalamus involved in feeding regulation and metabolic control as well as in brain regions that provide input to these hypothalamic nuclei (Konsman and Blomqvist, 2005; Ruud and Blomqvist, 2007), thus providing evidence that the anorexiacachexia syndrome involves activation changes in the neuronal circuits that control appetite and energy expenditure. However, the large complexity of the signalling network controlling integrity of the organism has made studies on the pathophysiology of, for example, the anorexia-cachexia syndrome on the central level a difficult task. Thus, in cancer anorexia, a number of hormones, cytokines, and other chemicals derived from the tumour or the host immune system, as well as changing nutrient concentrations, are found in the circulation and may trigger a variety of neurochemical events leading to an impaired balance between food intake and energy expenditure (Deans and Wigmore, 2005; Argilés et al, 2006; Tisdale, 2009).

Studies examining changes in hypothalamic gene transcription in several physiological or pathophysiological conditions (Wu et al, 1994; Lee et al, 1999; Komatsu et al, 2006; Mercader et al, 2008) have identified a variety of differentially expressed genes that may be involved in the control of food intake and energy metabolism. However, quite surprisingly, gene expression analysis of the hypothalami of tumour-bearing anorexic animals revealed minor transcriptional changes $v s$ those seen in caloric-restricted pair-fed animals, and that hence could be associated with the anorexiacachexia syndrome per se, and not being secondary to reduced food intake (Pourtau et al, 2011). However, from observations on gene expression changes, the corresponding functional involvement of these genes in the particular condition cannot be directly inferred because the amount of protein produced for a given amount of mRNA depends both on the gene it is transcribed from and on the current physiological state of that cell, and so far little has been done with respect to analysis of changes in protein expression in the hypothalamus during cancer-induced anorexia-cachexia (Wang et al, 2001). In an attempt to fill this gap of knowledge, we here, for the first time, implemented a proteomic approach for the analysis of changes in the hypothalamic proteome in a murine model of the cancer-induced anorexia-cachexia syndrome. By comparing the expression pattern in tumour-bearing anorexic mice with that in normal pair-fed mice and free-fed mice, differently expressed proteins with a potential role in the pathophysiology of the anorexia-cachexia syndrome or in the metabolic adaptation to caloric restriction were identified.

\section{MATERIALS AND METHODS}

Animal protocols. Methylcholanthrene-induced sarcoma-bearing mice (MCG 101), which is a well-characterised model of cancerinduced anorexia-cachexia (Gelin et al, 1991), were used in the present study.

Female 10-week-old C57BL/6 mice (B\&K Universal AB, Sollentuna, Sweden) weighing between 21.5 and $23.8 \mathrm{~g}(n=22)$ were housed one-to-one in standard plastic cages equipped with a raised bottom-wired grid (Tecniplast, Varese, Italy), supplemented with nesting material (Size-Nest, Datesand Ltd, Manchester, UK), in a temperature-controlled $\left(22 \pm 1{ }^{\circ} \mathrm{C}\right)$ environment and on a regular $12 \mathrm{~h}$ daylight schedule (with lights on at 0700 hours). Water and standard rodent chow were available ad libitum. All animals were adapted to the bottom-wired grids for at least 1 week, weight-matched, and divided into the following groups: for experiment 1 , the animals $(n=12)$ were divided into a tumourbearing $(n=4)$, a pair-fed $(n=4)$, and a free-fed group $(n=4)$. For experiment 2 , the animals $(n=10)$ were divided into a tumour-bearing $(n=5)$ and a free-fed group $(n=5)$. The mean initial body weight of the tumour-bearing mice was $22.87 \pm 0.26 \mathrm{~g}$, of the pair-fed mice $23.15 \pm 0.29 \mathrm{~g}$, and of the free-fed mice $22.58 \pm 0.23 \mathrm{~g}$. Under brief anaesthesia with $4 \%$ isoflurane, the mice in the tumour-bearing group were implanted subcutaneously on both sides of the dorsal midline with $3 \mathrm{~mm}^{3}$ large MCG 101 tumour fragments using a 16-gauge needle (Gelin et al, 1991). The animals in the pair-fed and free-fed groups were sham-implanted (received identical handling but without tumour implantation). Implanted tumour pieces were growing to palpable tumours in all tumour-bearing mice and all animals survived during the study period. Food intake and body weight were registered daily between 0900 and 1030 hours by weighing the leftover food in the food container and the food spillage collected on the bottom of the cage. Nine days after tumour implantation, the mice were killed with $\mathrm{CO}_{2}$. The brain was immediately removed, washed in ice-cold phosphate buffer, and chilled on ice. The hypothalamus was instantly dissected from the brain as described by Baker et al (1983), and snap frozen in liquid nitrogen. Samples were stored at $-80{ }^{\circ} \mathrm{C}$ until the analysis. The tumours in the tumour-bearing mice were separated from the dermis and underlying tissue, and measured.

All animal experiments were approved by the Animal Care and Use Committee at Linköping University and conformed to the standards in the Guide for the Care and Use of Laboratory Animals (Swedish Research Council).

Sample preparation and 2-DE. In order to avoid protein degradation, the frozen hypothalamus from each animal was suspended in ice-cold sample buffer containing $20 \mathrm{~mm}$ Tris, $7 \mathrm{~m}$ urea, $2 \mathrm{~m}$ thiourea, 4\% CHAPS, $10 \mathrm{~mm}$ 1,4-dithioerythritol (Sigma-Aldrich Sweden AB, Stockholm, Sweden), 0.5\% ampholytes 3-10 (Bio-Rad Laboratories, Hercules, CA, USA), and protease inhibitors (Complete, Roche Diagnostics Scandinavia AB, Stockholm, Sweden). The suspension was sonicated for $3 \times 30 \mathrm{~s}$ on ice and centrifuged at $15000 \mathrm{~g}$ for $30 \mathrm{~min}\left(4^{\circ} \mathrm{C}\right)$. The protein content in the supernatants was determined using the Bradford reagent (Pierce, Thermo Scientific, Rockford, IL, USA).

Immobilised $\mathrm{pH}$ gradient (IPG) strips $(17 \mathrm{~cm})$ with $\mathrm{pH}$ range (IPG 3-6, IPG 5-8, IPG 7-10, and IPG 3-10NL; Bio-Rad Laboratories) were used for isoelectric focusing (IEF). For IPG $3-6$, IPG 5-8, and IPG 3-10NL, the individual samples (200 $\mu \mathrm{g}$ of proteins) were loaded during rehydration of the IPG strips in $300 \mu \mathrm{l}$ (total volume) of IEF buffer $(7 \mathrm{M}$ urea; $2 \mathrm{M}$ thiourea; 4\% CHAPS; 10 mM 1,4-dithioerythritol; IPG buffer, $\mathrm{pH}$ 3-10) for $18 \mathrm{~h}$. Isoelectric focusing was carried out for a total of $60 \mathrm{kVh}$ (50 $\mu \mathrm{A}$ per IPG strip) using Multiphor II system (Pharmacia Biotech, Uppsala, Sweden). For IPG 7-10, the samples (200 $\mu \mathrm{g}$ of proteins) were diluted in total volume of $100 \mu$ l of IEF buffer containing IPG buffer ( $\mathrm{pH} 7-10)$ and loaded using paper bridges placed on the anodic end of the pre-rehydrated IPG 7-10 strips with a $0.5-\mathrm{cm}$ overlap. The samples absorbed in paper bridges were loaded into the IPG strips at $200 \mathrm{~V}$ for $16 \mathrm{~h}$. After the loading step, the bridges were removed and the strips were focused until they reached $52.5 \mathrm{kVh}$. The strips were then stored at $-80^{\circ} \mathrm{C}$ until run in the second dimension (SDS-PAGE). Before SDS-PAGE, the 
IPG strips were incubated in equilibration (EQ) solution ((6 M urea; 0.375 м Tris-HCl, pH 8.8; $2 \%$ SDS; $20 \%$ glycerol (Sigma-Aldrich) containing $2 \%$ dithiothreitol (DTT, Sigma-Aldrich)) and subsequently in EQ solution containing $2.5 \%$ iodoacetamide (Sigma-Aldrich) for $15 \mathrm{~min}$ each and immediately applied on the top of $13 \%$ polyacrylamide gels $(200 \times 200 \mathrm{~mm})$. SDS-PAGE was performed using Protean Plus Dodeca cell (Bio-Rad Laboratories) at $15 \mathrm{~mA}$ per gel for the first $1 \mathrm{~h}$ followed by $30 \mathrm{~mA}$ per gel for the rest of the separation.

Image capture, spot quantification, and statistical analysis. Gels were fixed in 50\% methanol containing 7\% acetic acid (Sigma-Aldrich) for $2 \mathrm{~h}$ followed by staining with SYPRO Ruby (Bio-Rad Laboratories) for $12 \mathrm{~h}$. After destaining, which removed background, gels were scanned and the images were captured as 16-bit TIFF files for further analysis. The experimental data sets comprised 12 gel images from 12 different animals (tumourbearing, pair-fed, and control group ( $n=4$ in each group)) for each of the three kinds of narrow $\mathrm{pH}$ range IPG strips. Analysis of the gel images, including background subtraction, spot volume normalisation, and differences in protein expression among the groups, was performed using PDQuest 8.01 software (Bio-Rad Laboratories). Visual inspection was used to check for artifactual spots, and merged or missed spots. Each matched spot was manually inspected and confirmed on each individual gel.

The amount of protein in a spot was normalised in each gel by dividing the raw quantity of each spot by the total intensity value of all the pixels in the image. The normalised spot volume is referred to as abundance. Only spots that were present in all gels from the same group were included in the statistical analysis. Data are presented as mean \pm s.e.m. Statistical differences between the groups were assessed using Student's $t$-test with $P<0.02$ considered as significant.

The protein spots that passed these statistical criteria were further analysed and identified by mass spectrometry. Ten additional two-dimensional gel images from tumour-bearing and free-fed control mice included in the independent animal experiment ( $n=5$ animals per group) using IPG $3-10 \mathrm{NL}$ were analysed in order to validate the obtained results.

In-gel digestion and mass spectrometric identification. Protein spots excised from SYPRO Ruby-stained gels were destained with $100 \mathrm{~mm}$ ammonium bicarbonate in 50\% acetonitrile (AcN; SigmaAldrich), and then washed with $100 \% \mathrm{AcN}$ and dried on SpeedVac (Christ, Osterode am Harz, Germany). Before enzymatic digestion of proteins, in-gel reduction and alkylation reactions were carried out with $10 \mathrm{~mm}$ DTT in $100 \mathrm{~mm} \mathrm{NH}_{4} \mathrm{HCO}_{3}\left(45 \mathrm{~min}, 56^{\circ} \mathrm{C}\right)$ and subsequently with $50 \mathrm{~mm}$ iodoacetamide in $100 \mathrm{~mm} \mathrm{NH}_{4} \mathrm{HCO}_{3}$ $\left(30 \mathrm{~min}\right.$ in the dark, $\left.20^{\circ} \mathrm{C}\right)$. Sequencing grade-modified trypsin (Promega, Madison, WI, USA), $0.1 \mu \mathrm{g}$ in $40 \mathrm{~mm} \mathrm{NH}_{4} \mathrm{HCO}_{3} / 10 \%$ AcN, was added to the dry gel pieces and incubated for $20 \mathrm{~h}$ at $37^{\circ} \mathrm{C}$.

The resulting peptides were extracted with $2 \%$ formic acid (FA) in AcN (Sigma-Aldrich), and then twice with 100\% AcN for $30 \mathrm{~min}$ at room temperature. The extracted peptides were dried on
SpeedVac (Christ) and subsequently dissolved in $5 \mu \mathrm{l} 0.1 \%$ FA in $50 \% \mathrm{AcN}$. The resulting peptide mixtures were analysed by liquid chromatography-tandem mass spectrometry (LC-MS/MS) using nano-flow HPLC system (EASY-nLC; Bruker Daltonics, Bremen, Germany) on a $20 \mathrm{~mm} \times 100 \mu \mathrm{m}$ (particle size, $5 \mu \mathrm{m}$ ) C18 precolumn followed by a $100 \mathrm{~mm} \times 75 \mu \mathrm{m} \mathrm{C18}$ column (particle size, $5 \mu \mathrm{m})$ at a flow rate of $300 \mathrm{nlmin}^{-1}$, using a linear gradient starting with $0.1 \%$ FA (solvent A) and ending with $0.1 \%$ FA in $100 \%$ AcN (solvent B) for 45 min. HTCultra PTM Discovery System (Bruker Daltonics) was used for data acquisition. The raw data from tandem MS analyses were processed using DataAnalysis 3.4 software (Bruker Daltonics) and the resulting Mascot generic files were used for the search in NCBI protein database on the Mascot server (http://www.matrixscience.com). The search parameters were taxonomy: 'Rodents'; enzyme: trypsin with permission of one missed cleavage site; fixed modification: 'Carbamidomethyl (C)'; variable modifications: 'Protein acetylation', and 'Oxidation (M)'; peptide tolerance: $\pm 0.8 \mathrm{Da}$ for $\mathrm{MS}$ data and $\pm 0.8 \mathrm{Da}$ for MS/MS data. The significance threshold for MASCOT ion identification was set to $P<0.05$.

Proteins with at least one peptide passing the required bold red criteria were considered to be positively matched.

\section{RESULTS}

Tumour implantation resulted in progressive reduction in food intake, with the tumour-bearing mice consuming about 30\% less food than free-fed mice at day 9 after implantation when they were killed. Pair-fed mice, whose food intake was restricted to the amount consumed by their tumour-bearing littermates, displayed a food intake at day 9 that was slightly lower than that of tumourbearing mice (Table 1).

To examine whether protein expression in the hypothalamus was altered in tumour-bearing anorexic mice compared with free-fed control mice and caloric-restricted pair-fed mice, extracts from the hypothalami were separated by high-resolution two-dimensional electrophoresis (2-DE) using three different narrow $\mathrm{pH}$ range IPG strips (IPG 3-6, IPG 5-8, and IPG 7-10; experiment 1). Separated proteins were visualised by SYPRO Ruby stain and detected using PDQuest 2-D analysis software. Image analysis of 24 gels derived from 12 different animals divided into tumour-bearing, pair-fed, and free-fed groups ( $n=4$ per group) revealed $\sim 518$ valid protein spots at $\mathrm{pH}$ 3-6 and 1004 protein spots at $\mathrm{pH}$ range 5-8 (Supplementary Figures 1 and 2). Only spots present in all gels from mice of the same group were analysed. The image analysis revealed 16 protein spots with $P<0.02$ that were differentially expressed between the tumour-bearing mice and free-fed mice (Figure 1). Three identical spots (spot 5, 10, and 12) were found independently in gels using IPG 3-6 and IPG 5-8. The expression pattern of these three proteins was also identical in gels with both $\mathrm{pH}$ gradients demonstrating high reproducibility of the obtained results. Despite excellent separation of basic proteins

\begin{tabular}{|l|c|c|c|c|c}
\hline Food intake & Tumour-bearing & Pair-fed & Free-fed & Tumour-bearing & Free-fed \\
\hline Initial & $4.32 \pm 0.24$ & $4.12 \pm 0.24$ & $3.89 \pm 0.11$ & $3.86 \pm 0.343$ & $3.36 \pm 0.16$ \\
\hline Final & $2.92 \pm 0.15$ & $2.43 \pm 0.15$ & $4.09 \pm 0.17$ & $2.80 \pm 0.09$ & $4.14 \pm 0.18$ \\
\hline
\end{tabular}

Figures show the amount of food consumed ( $\mathrm{g} \pm$ s.e.m.) by the mice the day before tumour or sham implantation ('initial') and day 9 after implantation ('final'). 

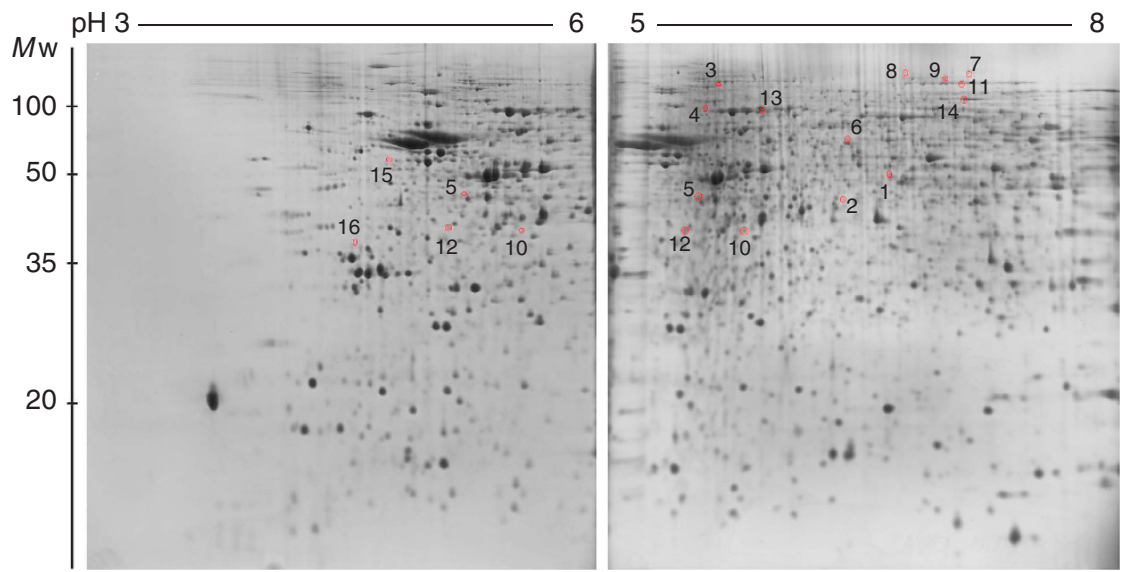

Figure 1. 2-D proteome reference maps obtained using narrow pH range IPG strips. Proteins of mouse hypothalamus (200 $\mu \mathrm{g})$ were separated on pH 3-6 and pH 5-8 IPG strips in the first dimension and by 13\% SDS-PAGE gels in the second dimension. Proteins were stained with SYPRO Ruby. Differentially expressed spots $(P<0.02)$ that are labelled and numbered were identified by LC-MS/MS (see Table 2 and Supplementary Tables 1 and 2). The spots 5,10 , and 12 were found independently in gels with both kinds of $\mathrm{pH}$ range.

$\mathrm{pH} 3 \longrightarrow 10$

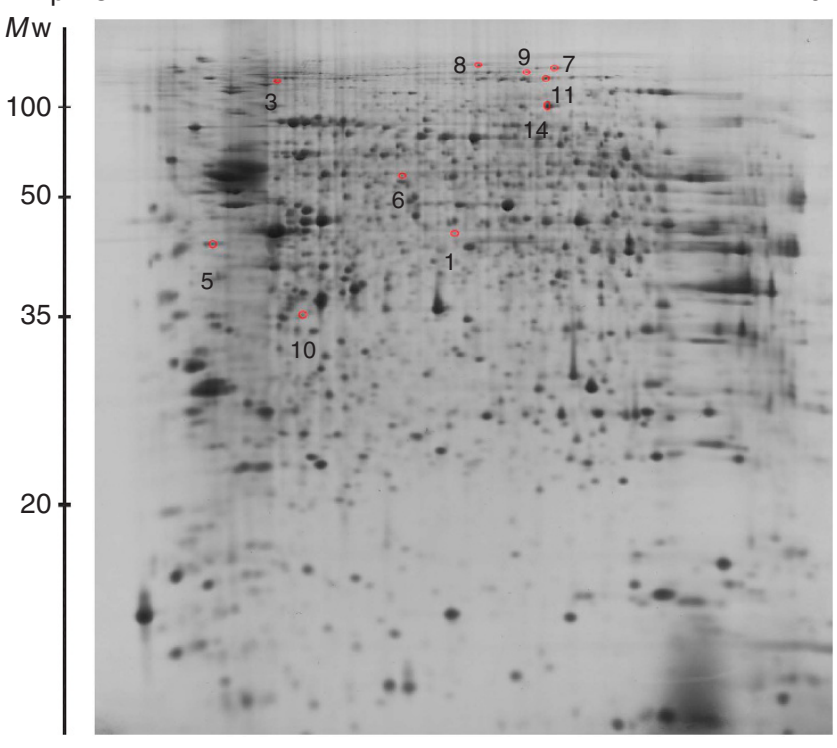

Figure 2. Representative gel image from the independent experiment using IPG 3-10NL strips. This independent experiment validated the data acquired from gels with narrow $\mathrm{pH}$ range. Ten protein spots were identified to be differentially expressed $(P<0.05)$ between anorexic tumour-bearing mice $(n=5)$ and free-fed mice $(n=5)$. The expression pattern of these proteins (marked in red) was identical to that in the gels with narrow $\mathrm{pH}$ range. Data for the six other proteins that were identified in gels using IPG 3-6 and IPG 5-8 strips could not be validated as they were not visible in the gels with wide $\mathrm{pH}$ range owing to much lower resolution capacity of IPG 3-10NL strips. Proteins of hypothalamus $(150 \mu \mathrm{g})$ were resolved in 13\% SDS-PAGE gels in the second dimension and stained with SYPRO Ruby.

using IPG 7-10 strips (Supplementary Figure 3), the gel images from that separation were not further analysed because of observed differences in quantity of loaded proteins in gels using paperloading bridges that prevented regular 2-D image analysis. To avoid false-positive finding due to mass significance, 10 more gels using IPG $3-10 \mathrm{NL}$ and prepared from a separate experiment involving five tumour-bearing mice and five free-fed control mice ( $n=5$ per group) were examined (one gel per animal) and used for validation (experiment 2; Figure 2; Supplementary Figure 4). The expression pattern of 10 of the 16 protein spots displayed a significantly different expression in tumour-bearing mice $(P<0.05)$ compared with free-fed mice in this analysis. The other six proteins that were differentially expressed in the narrow $\mathrm{pH}$ range IPG strips were not visible in the gels with the wide $\mathrm{pH}$ range because of their much lower resolution capacity.

As a next step, we examined which of the 10 spots with a verified expression difference in tumour-bearing mice compared with free-fed mice that also differed $(P<0.05)$ when the expression was compared with that in food-restricted pair-fed mice. Finally, the selected spots were analysed by LC-MS/MS. Complete nomenclature of the differently expressed proteins is given in Table 2 along with the fold change of expression for these proteins in the hypothalami of tumour-bearing mice $v$ f free-fed mice and pair-fed mice, respectively. Data for the six spots that were identified in the IPG 3-6 and IPG 5-8 strips but that could not be validated in the independent samples (IPG 3-10NL) are given in Supplementary Table 1 .

A change in expression in anorexic tumour-bearing mice that was significantly different $v s$ both free-fed and pair-fed mice was found for three proteins, dynamin 1, which was upregulated 2.7fold in the tumour-bearing mice compared with free-fed mice and 1.8 -fold when compared with pair-fed mice; hexokinase, which was upregulated 2.1- and 1.9-fold, respectively; and pyruvate carboxylase, which was upregulated 2.3- and 1.5-fold, respectively (Table 2; Figures 3 and 4). The other seven protein spots that were validated to be differently expressed in tumour-bearing mice compared with free-fed mice, but whose expression did not differ significantly compared with that seen in pair-fed mice included $\mathrm{N}$-ethylmaleimide-sensitive factor, and oxoglutarate dehydrogenase, both of which were upregulated. Three other proteins, guanine nucleotide-binding protein $\mathrm{G} \alpha_{0}$ subunit, heat-shock $70 \mathrm{kDa}$ cognate protein (Hsc70), and selenium-binding protein 1 were downregulated (Table 2; Figures 3 and 4). The 2-DE data analysis revealed two additional spots (3 and 10) that also were downregulated, but for these two proteins, results from MASCOT search (Supplementary Table 2) could not be obtained.

\section{DISCUSSION}

Using 2-DE analyses and LC-MS/MS, we here examined the global protein expression in the brain's metabolic control centre, the hypothalamus, in a model of cancer-induced anorexia. We identified 10 proteins that were differentially expressed in 


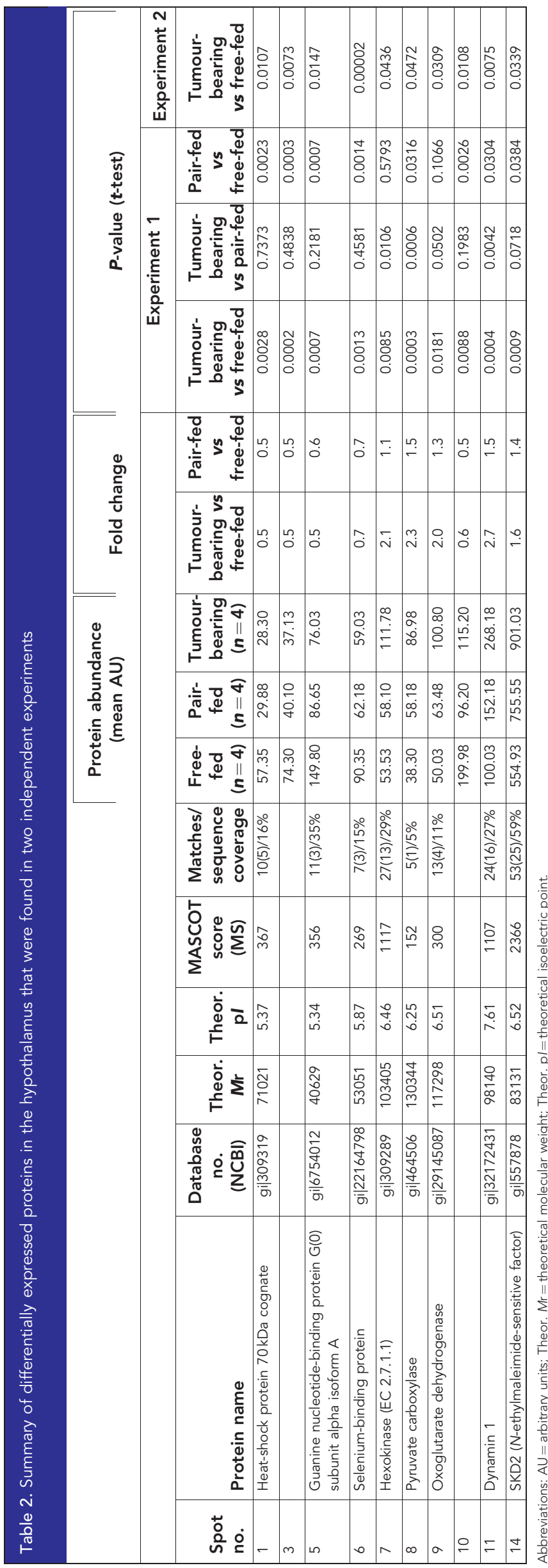

the hypothalami of tumour-bearing anorexic mice compared with free-fed mice. Although false-positive results because of mass significance is an obstacle in all unbiased gene or protein expression analyses, the present approach reduced the risk for type 1 errors to $<5 \%$ of the 16 proteins that were initially identified (that is, $<1$ protein) by re-examining these 16 proteins in a separate, independent experiment. For three of the identified proteins that differed in expression between tumour-bearing and free-fed mice, dynamin 1, hexokinase, and pyruvate carboxylase, the expression differed also $v s$ that in food-restricted pair-fed mice, indicating that changes in the expression of these proteins may be specifically related to tumour-induced anorexia. As will be discussed below, these proteins are involved in melanocortin signalling and glucose metabolism. Of the other identified proteins, guanine nucleotide-binding protein $\mathrm{G} \alpha_{0}$-subunit and Hsc70 may also be related to melanocortin signalling, whereas $\mathrm{N}$-ethylmaleimide-sensitive factor, oxoglutarate dehydrogenase, and seleniumbinding protein 1 are related to dopamine turnover and intermediary metabolism. However, the observed expression changes may have been secondary to the reduced food intake in the tumour-bearing mice, as the expression of these proteins did not differ from that in pair-fed mice. Notably, expression changes in the part of hypothalamic proteome containing basic proteins was for technical reasons not possible to analyse (see above), and may hence have escaped detection. This part of proteome contains, for example, the prostaglandin $\mathrm{EP}_{1}$ and $\mathrm{EP}_{3}$ receptor subtypes that along with the melanocortin-4 receptor (MC4R) only can be detected in gels of that $\mathrm{pH}$ range.

Below we discuss, in some details, the possible functional roles of the identified proteins in the context of impaired central control of energy homoeostasis in the pathophysiology of the anorexiacachexia syndrome or during adaptation of the brain tissue to restricted nutrient availability.

Dynamin 1. The finding that the expression of dynamin 1 was selectively upregulated in tumour-bearing anorexic mice is intriguing because this multifunctional protein has also been shown to be required for the internalisation of the MC4R. Thus, dominant-negative mutants of dynamin 1 dramatically prevented the $\alpha$-melanocyte-stimulated hormone-mediated internalisation of the MC4R receptor in HEK 293 cells (Shinyama et al, 2003). The MC4R is critical for the control of food intake (Cummings and Schwartz, 2000; Chen et al, 2000a, b), and mice lacking the MC4R have increased appetite and develop pronounced obesity (Butler and Cone, 2002), whereas MC4R stimulation has an appetitereducing effect (Marks et al, 2001). Of particular interest in the present context is the report that mice with MC4R deletion are protected against tumour-induced anorexia and weight loss (Marks et al, 2001) and the finding of a blunted gene expression of the endogenous melanocortin antagonist agouti-related peptide in tumour-bearing rats (Pourtau et al, 2011). Taken together with these observations, the present data suggest a dynamin 1-dependent increased melanocortin signalling in tumour-bearing mice, a hypothesis that could be tested in functional in vivo experiments.

It is also well established that inflammatory signalling and inflammatory-induced prostaglandins have a central role in tumorigenesis and have been proposed as key mediators of cancer anorexia (Gelin et al, 1991, Ruud et al, 2013a). The biological function of prostaglandin $\mathrm{E}_{2}\left(\mathrm{PGE}_{2}\right)$ is mediated via four G-protein-coupled receptors $\mathrm{EP}_{1}-\mathrm{EP}_{4}$ (Sugimoto and Narumiya, 2007). Ligand-induced activation of $\mathrm{EP}_{4}$ receptor signalling in the central nervous system has been shown responsible for suppressive effect of $\mathrm{PGE}_{2}$ on food intake in mice (Ohinata et al, 2006). Interestingly, dynamin 1 has also been demonstrated to be required for $\mathrm{PGE}_{2}$-induced internalisation of $\mathrm{EP}_{4}$ receptor resulting in rapid activation of mitogen-activated protein kinase (Desai and 


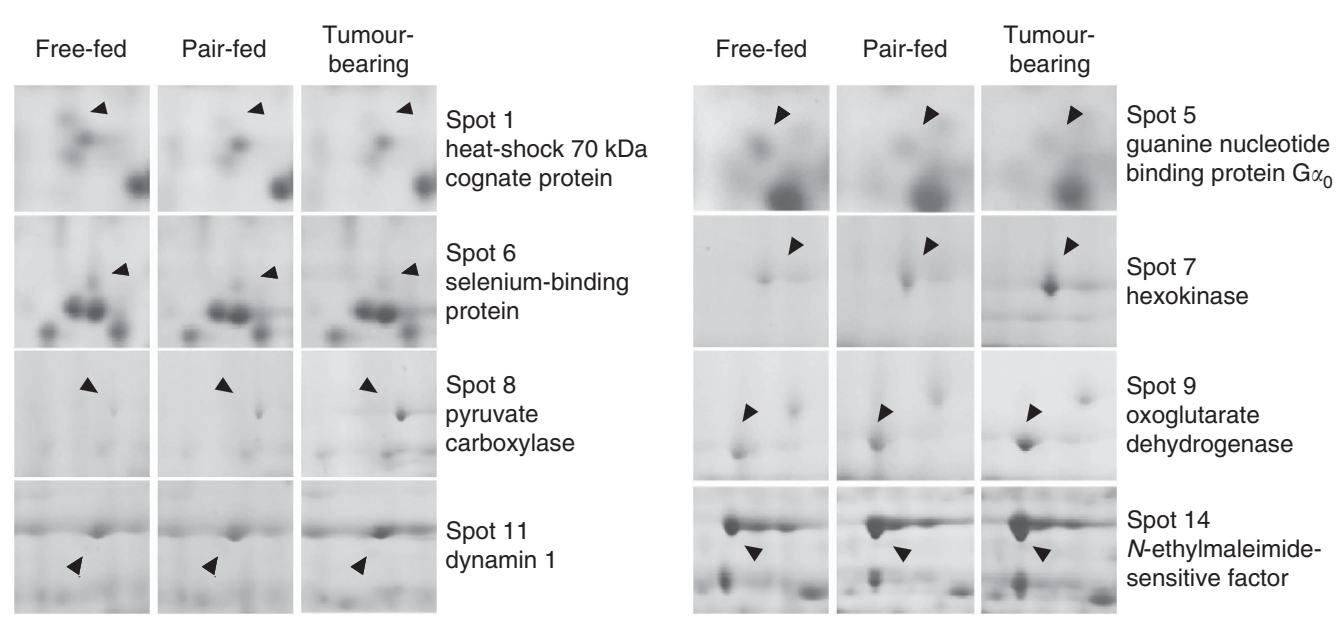

Figure 3. Microphotographs of protein spots that differed in intensity between tumour-bearing mice, pair-fed mice, and free-fed mice.
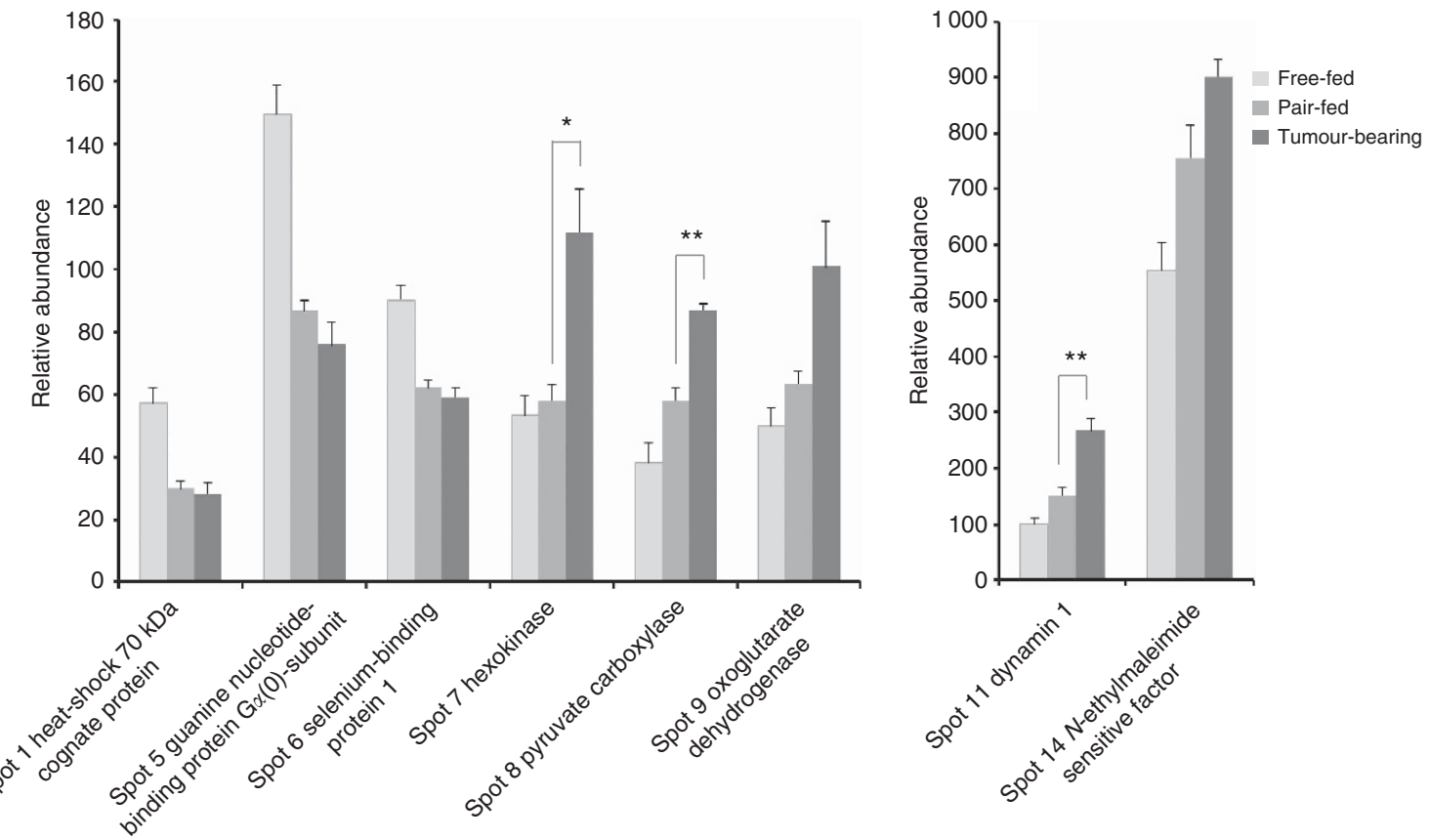

Figure 4. Proteins differentially expressed in the hypothalamus between tumour-bearing mice and free-fed mice that were identified in two independent experiments. Each bar represents the mean of the relative spot volume intensity \pm s.e.m. $(n=4)$. ${ }^{\star} P<0.02$ and ${ }^{\star \star} P<0.01$.

Ashby, 2001). This observation may suggest that increased $\mathrm{EP}_{4}$ receptor signalling could be another possible reason for the increased dynamin 1 expression in the hypothalami of tumourbearing mice in the present study. However, the importance of the $\mathrm{EP}_{4}$ receptor as well as other $\mathrm{EP}$ receptor subtypes in the pathogenesis of cancer anorexia, at least in a mouse tumour model, has not been confirmed (Wang et al, 2005, Ruud et al, 2013a).

Hexokinase. Hexokinase, which also was selectively upregulated in tumour-bearing mice, is the first enzyme required in the glucose metabolism and is the main regulator of the glycolytic rate in the brain (Lowry and Passonneau, 1964). An increased rate of gluconeogenesis and hyperglycaemia are common in cancer patients mainly because of elevated activity of the Cori cycle in the liver, which accounts for the disposal of the lactate produced by the tumour (Tayek, 1992; Tisdale, 2000).

The changes in carbohydrate metabolism in cancer patients are probably because of increased metabolic demands of the highly proliferative tumour cells. In the present study, we have found hexokinase expression more than 2-fold upregulated specifically in the hypothalami of tumour-bearing mice. We hypothesise that this may likely be owing to potentially occurring hyperglycaemia or as a protection mechanism of neurons against increased oxidative stress because of accumulation of tryptophan in the brain that has been shown in this model (Wang et al, 2003). Increased hexokinase expression in the hypothalami of tumour-bearing mice in the present study is apparently a cancer-related process because the expression of that protein in pair-fed animals was similar to that in the free-fed group.

Pyruvate carboxylase. The third identified protein, the expression of which was significantly different in tumour-bearing mice from that in both pair-fed and free-fed mice, pyruvate carboxylase, catalyses carboxylation of pyruvate to form oxaloacetate and is controlling gluconeogenesis. During fasting or starvation, and analogically also in cancer anorexia, the brain and other tissues are dependent on endogenous glucose generated by gluconeogenesis, utilising alanine, lactate, glycerol, and glutamine (Rothman et al, 1991). 
An increased use of 3-hydroxybutyrate by the brain suggests that ketone bodies may be utilised as a metabolic fuel during the cancer-bearing state (Mulligan and Tisdale, 1991). The stimulatory effect of 3-hydroxybutyrate on pyruvate carboxylation has been demonstrated (Siess, 1985), and the expression of pyruvate carboxylase in astrocytes suggests a utilisation of these non-carbohydrate precursors converting them into glycogen (Schmoll et al, 1995; Wiesinger et al, 1997). Moreover, pyruvate carboxylase is necessary for the astrocytic production of glutamine via the glutamate/glutamine cycle (Cooper and Plum, 1987). Although the expression of pyruvate carboxylase in tumourbearing mice was upregulated not only when compared with freefed mice (2.3-fold) but also when compared with pair-fed mice (1.5-fold), there was also an upregulation in pair-fed mice $v s$ free-fed mice (1.5-fold), which would be consistent with reduced food intake as the primary underlying mechanism.

Guanine nucleotide-binding protein $\mathbf{G} \alpha_{0}$ subunit. Loss of adipose tissue in cancer cachexia is primarily caused by increased lipolysis (Shaw and Wolfe, 1987; Klein and Wolfe, 1990; Islam-Ali et al, 2001) following an enhanced stimulation of adenylyl cyclase, because of an increased expression of the stimulatory guanine nucleotide-binding protein $\mathrm{G} \alpha_{\mathrm{s}}$, and decreased expression of the inhibitory $\mathrm{G} \alpha_{0}$ form (Islam-Ali et al, 2001). We found that $\mathrm{G} \alpha_{0}$ in hypothalamus was on average 2 -fold downregulated in anorexic and pair-fed animals. The importance of $\mathrm{G} \alpha_{0}$ in the regulation of food intake has also been shown by ventricular administration of $\mathrm{G} \alpha_{0}$ antisense probe, which resulted in reduced body weight recovery after a 24 -h period of food deprivation in rats (Hadjimarkou et al, 2002). It is also well established that G-proteins have an important role in regulation of food intake as they are involved in melanocortin signalling through coupling to MC4R (Tao, 2010).

Heat-shock $70 \mathrm{kDa}$ cognate protein. Hsc70 has also been shown to be related to MC4R signalling as increased Hsc70 levels promoted cell surface localisation of the wild-type or mutant receptor (Meimaridou et al, 2011). However, the present study identified the Hsc70 levels as significantly reduced both in tumourbearing mice but also in pair-fed mice, which would indicate attenuated melanocortin signalling in both groups and hence increased appetite, contrary to the anorexia seen in the tumourbearing mice. Thus, other function for this protein than the regulation of MC4R signalling should also be considered. It is well known that $\mathrm{Hsc70}$ is part of a proteolytic machinery called chaperone-mediated autophagy, which can degrade unnecessary proteins and provide amino acids available for necessary cell processes during prolonged nutrient deprivation (Majeski and Dice, 2004; Finn and Dice, 2006; Orenstein and Cuervo, 2010). However, activation of chaperone-mediated autophagy induced by starvation is tissue-dependent with preferential activation in the liver, heart, kidney, and spleen but it does not have a considerable impact on the brain (Cuervo, 2004). It is tempting to hypothesise that downregulated Hsc70 in the hypothalami of anorexic or caloric-restricted mice may be a protective mechanism against activation of 'self-eating' processes in the brain during the times of nutrient deprivation, such as cancer anorexia or food deprivation.

$\mathrm{N}$-ethylmaleimide-sensitive factor. The upregulation of $\mathrm{N}$-ethylmaleimide-sensitive factor found in the present study may be related to changes in dopamine signalling as this protein has been shown to be important for the membrane localisation of the $D_{1}$ receptor (Chen and Liu, 2010). Abnormal dopaminergic neurotransmission has been suggested to have a significant role in cancer anorexia-modulated feeding behaviour, as dopaminergic $\mathrm{D}_{1}$ and $\mathrm{D}_{2}$ receptor subtypes were found to be upregulated in the hypothalami of anorexic tumour-bearing rats and their selective inhibition had a considerable effect on the regulation of meal size, meal number, and thus food intake in these animals (Sato et al, 2001). Moreover, increased dopamine receptor signalling has also been found in food-restricted rats (Carr et al, 2003), thereby fitting well with changes in $\mathrm{N}$-ethylmaleimide-sensitive factor seen in the present study.

Oxoglutarate dehydrogenase. Oxoglutarate dehydrogenase, which is a critical enzyme of the intermediary metabolism, was upregulated in the present study. It catalyses conversion of $\alpha$-ketoglutarate into succinil-CoA, which is a critical step in the TCA cycle. Increased plasma levels of glutamate via conversion to $\alpha$-ketoglutarate may be a source for energy production in cancer patients when the normal functioning of TCA cycle is impaired by increased oxidative stress (Tretter and Adam-Vizi, 2005).

It has been shown that MCG 101-bearing mice also develop alterations in the brain tryptophan/serotonin metabolism during tumour progression (Wang et al, 2003) and that tryptophan can contribute to cancer anorexia by stimulating hypothalamic serotonergic activity and promote oxidative stress because of free radicals generated by tryptophan degradation via the kynurenine pathway (Laviano et al, 2007). An inducible effect of $\alpha$-ketoglutarate and glutamate on the expression of the oxoglutarate dehydrogenase gene has been described (Sheu and Blass, 1999) and could be the cause of the upregulation of oxoglutarate dehydrogenase in the hypothalami of tumour-bearing mice that was seen in the present study. No such upregulation was seen in pair-fed mice, and although the difference in expression between tumour-bearing mice and the food-restricted pair-fed mice did not reach statistical significance, it was borderline $(P=0.0502)$, potentially indicating a selective effect in the tumour-bearing mice.

Selenium-binding protein 1. An additional differentially regulated protein that was identified was selenium-binding protein 1 .

It was downregulated in both tumour-bearing and pair-fed mice. However, little is known about its relation to food intake or metabolic control.

\section{CONCLUSION}

The present study demonstrates that during tumour-induced anorexia-cachexia, the hypothalamic proteome undergoes changes in expression of proteins that are involved in melanocortin and inflammatory signalling and glucose metabolism. The obtained results are consistent with the generally accepted framework of the pathogenesis of cancer anorexia-cachexia as a multifactorial syndrome, with many of the primary events driving this syndrome being mediated via the central nervous system and include inflammation-related anorexia and hypoanabolism or hypercatabolism (Fearon et al, 2013).

The identified proteins are new potential candidate molecules in cancer-induced anorexia. Functional studies of the role of these proteins in the regulation of food intake could provide critical information on the mechanisms behind impaired hypothalamic regulation of energy homoeostasis during the development of the anorexia-cachexia syndrome, and could help identifying novel therapeutic agents for the treatment of this debilitating condition.

However, it should be noted that the present study examined changes that occurred at a time point when a decrease in food intake was well evident. It is possible that examination of the proteome at other time points, such as just before the decrease in food intake, will reveal yet additional changes that also may be relevant for the development of the anorexia-cachexia syndrome. 


\section{ACKNOWLEDGEMENTS}

We thank Dr Johan Ruud for sharing of some material included in the study. We also thank Dr Maria Turkina for helpful comments on reading the manuscript. This work was supported by the Swedish Cancer Foundation, Grant number 120553 and the Swedish Research Council, Grant number 12X-07879.

\section{REFERENCES}

Argilés JM, Busquets S, López-Soriano FJ (2006) Cytokines as mediators and targets for cancer cachexia. Cancer Treat Res 130: 199-217.

Baker H, Joh TH, Ruggiero DA, Reis DJ (1983) Variations in number of dopamine neurons and tyrosine hydroxylase activity in hypothalamus of two mouse strains. J Neurosci 3: 832-843.

Body JJ (1999) The syndrome of anorexia-cachexia. Curr Opin Oncol 11: 255-260.

Bosaeus I, Daneryd P, Svanberg E, Lundholm K (2001) Dietary intake and resting energy expenditure in relation to weight loss in unselected cancer patients. Int J Cancer 93: 380-383.

Butler AA, Cone RD (2002) The melanocortin receptors: lessons from knockout models. Neuropeptides 36: 77-84.

Carr KD, Tsimberg Y, Berman Y, Yamamoto N (2003) Evidence of increased dopamine receptor signaling in food-restricted rats. Neuroscience 119: 1157-1167.

Chen AS, Marsh DJ, Trumbauer ME, Frazier EG, Guan XM, Yu H, Rosenblum CI, Vongs A, Feng Y, Cao L, Metzger JM, Strack AM, Camacho RE, Mellin TN, Nunes CN, Min W, Fisher J, Gopal-Truter S, MacIntyre DE, Chen HY, Van der Ploeg LH (2000a) Inactivation of the mouse melanocortin-3 receptor results in increased fat mass and reduced lean body mass. Nat Genet 26: 97-102.

Chen AS, Metzger JM, Trumbauer ME, Guan XM, Yu H, Frazier EG, Marsh DJ, Forrest MJ, Gopal-Truter S, Fisher J, Camacho RE, Strack AM, Mellin TN, MacIntyre DE, Chen HY, Van der Ploeg LH (2000b) Role of the melanocortin-4 receptor in metabolic rate and food intake in mice. Transgenic Res 9: 145-154.

Chen S, Liu F (2010) Interaction of dopamine D1 receptor with $\mathrm{N}$-ethylmaleimide-sensitive factor is important for the membrane localization of the receptor. J Neurosci Res 88: 2504-2512.

Cooper AJ, Plum F (1987) Biochemistry and physiology of brain ammonia. Physiol Rev 67: 440-519.

Cuervo AM (2004) Autophagy: many paths to the same end. Mol Cell Biochem 263: $55-72$.

Cummings DE, Schwartz MW (2000) Melanocortins and body weight: a tale of two receptors. Nat Genet 26: 8-9.

Deans C, Wigmore SJ (2005) Systemic inflammation, cachexia and prognosis in patients with cancer. Curr Opin Clin Nutr Metab Care 8: 265-269.

Desai S, Ashby B (2001) Agonist-induced internalization and mitogenactivated protein kinase activation of the human prostaglandin EP4 receptor. FEBS Lett 501: 156-160.

Fearon K, Arends J, Baracos V (2013) Understanding the mechanisms and treatment options in cancer cachexia. Nat Rev Clin Oncol 10(2): 90-99.

Finn PF, Dice JF (2006) Proteolytic and lipolytic responses to starvation. Nutrition 22: 830-844.

Gelin J, Andersson C, Lundholm K (1991) Effects of indomethacin, cytokines, and cyclosporin A on tumor growth and the subsequent development of cancer cachexia. Cancer Res 51: 880-885.

Hadjimarkou MM, Silva RM, Rossi GC, Pasternak GW, Bodnar RJ (2002) Feeding induced by food deprivation is differentially reduced by G-protein $\alpha$-subunit antisense probes in rats. Brain Res 955: 45-54.

Islam-Ali B, Khan S, Price SA, Tisdale MJ (2001) Modulation of adipocyte G-protein expression in cancer cachexia by a lipid-mobilizing factor (LMF). Br J Cancer 85: 758-763.

Klein S, Wolfe RR (1990) Whole-body lipolysis and triglyceride-fatty acid cycling in cachectic patients with esophageal cancer. J Clin Invest 86: 1403-1408.
Komatsu T, Chiba T, Yamaza H, To K, Toyama H, Higami Y, Shimokawa I (2006) Effect of leptin on hypothalamic gene expression in calorierestricted rats. J Gerontol A Biol Sci Med Sci 61: 890-898.

Konsman JP, Blomqvist A (2005) Forebrain patterns of c-Fos and FosB induction during cancer-associated anorexia-cachexia in rat. Eur $J$ Neurosci 21: 2752-2766.

Laviano A, Meguid MM, Preziosa I, Rossi Fanelli F (2007) Oxidative stress and wasting in cancer. Curr Opin Clin Nutr Metab Care 10: 449-456.

Lee CK, Klopp RG, Weindruch R, Prolla TA (1999) Gene expression profile of aging and its retardation by caloric restriction. Science 285: 1390-1393.

Lowry OH, Passonneau JV (1964) The relationships between substrates and enzymes of glycolysis in brain. J Biol Chem 239: 31-42.

Majeski AE, Dice JF (2004) Mechanisms of chaperone-mediated autophagy. Int J Biohcem Cell Bio 36: 2435-2444.

Marks DL, Ling N, Cone RD (2001) Role of the central melanocortin system in cachexia. Cancer Res 61: 1432-1438.

Meimaridou E, Gooljar SB, Ramnarace N, Anthonypillai L, Clark AJ, Chapple JP (2011) The cytosolic chaperone Hsc70 promotes traffic to the cell surface of intracellular retained melanocortin-4 receptor mutants. Mol Endocrinol 25: 1650-1660.

Mercader JM, Lozano JJ, Sumoy L, Dierssen M, Visa J, Gratacos M, Estivill X (2008) Hypothalamus transcriptome profile suggests an anorexia-cachexia syndrome in the anx/anx mouse model. Physiol Genomics 35: 341-350.

Mulligan HD, Tisdale MJ (1991) Metabolic substrate utilization by tumour and host tissues in cancer cachexia. Biochem J 277(Pt 2): 321-326.

Ohinata K, Suetsugu K, Fujiwara Y, Yoshikawa M (2006) Activation of prostaglandin E receptor EP4 subtype suppresses food intake in mice. Prostag Oth Lipid M 81: 31-36.

Orenstein SJ, Cuervo AM (2010) Chaperone-mediated autophagy: molecular mechanisms and physiological relevance. Semin Cell Dev Biol 21: 719-726.

Pourtau L, Leemburg S, Roux P, Leste-Lasserre T, Costaglioli P, Garbay B, Drutel G, Konsman JP (2011) Hormonal, hypothalamic and striatal responses to reduced body weight gain are attenuated in anorectic rats bearing small tumors. Brain Behav Immun 25: 777-786.

Rothman DL, Magnusson I, Katz LD, Shulman RG, Shulman GI (1991) Quantitation of hepatic glycogenolysis and gluconeogenesis in fasting humans with 13C NMR. Science 254: 573-576.

Ruud J, Blomqvist A (2007) Identification of rat brainstem neuronal structures activated during cancer-induced anorexia. J Comp Neurol 504: 275-286.

Ruud J, Nilsson A, Engstrom Ruud L, Wang W, Nilsberth C, Iresjo BM, Lundholm K, Engblom D, Blomqvist A (2013a) Cancer-induced anorexia in tumor-bearing mice is dependent on cyclooxygenase-1. Brain Behav Immun 29: 124-135.

Ruud J, Wilhelms DB, Nilsson A, Eskilsson A, Tang YJ, Strohle P, Caesar R, Schwaninger M, Wunderlich T, Backhed F, Engblom D, Blomqvist A (2013b) Inflammation- and tumor-induced anorexia and weight loss require MyD88 in hematopoietic/myeloid cells but not in brain endothelial or neural cells. FASEB J 27: 1973-1980.

Sato T, Meguid MM, Fetissov SO, Chen C, Zhang L (2001) Hypothalamic dopaminergic receptor expressions in anorexia of tumor-bearing rats. Am J Physiol Regul Integr Comp Physiol 281: R1907-R1916.

Schmoll D, Fuhrmann E, Gebhardt R, Hamprecht B (1995) Significant amounts of glycogen are synthesized from 3-carbon compounds in astroglial primary cultures from mice with participation of the mitochondrial phosphoenolpyruvate carboxykinase isoenzyme. Eur J Biochem 227: 308-315.

Shaw JH, Wolfe RR (1987) Fatty acid and glycerol kinetics in septic patients and in patients with gastrointestinal cancer. The response to glucose infusion and parenteral feeding. Ann Surg 205: 368-376.

Sheu KF, Blass JP (1999) The alpha-ketoglutarate dehydrogenase complex. Ann N Y Acad Sci 893: 61-78.

Shinyama H, Masuzaki H, Fang H, Flier JS (2003) Regulation of melanocortin-4 receptor signaling: agonist-mediated desensitization and internalization. Endocrinology 144: 1301-1314.

Siess EA (1985) Stimulation by 3-hydroxybutyrate of pyruvate carboxylation in mitochondria from rat liver. Eur J Biochem 152: 131-136.

Sugimoto Y, Narumiya S (2007) Prostaglandin E receptors. J Biol Chem 282: $11613-11617$.

Tao YX (2010) The melanocortin-4 receptor: physiology, pharmacology, and pathophysiology. Endocr Rev 31: 506-543.

Tayek JA (1992) A review of cancer cachexia and abnormal glucose metabolism in humans with cancer. J Am Coll Nutr 11: 445-456. 
Tisdale MJ (2000) Metabolic abnormalities in cachexia and anorexia. Nutrition 16: 1013-1014.

Tisdale MJ (2009) Mechanisms of cancer cachexia. Physiol Rev 89: 381-410.

Toni R, Malaguti A, Benfenati F, Martini L (2004) The human hypothalamus: a morpho-functional perspective. J Endocrinol Invest 27: 73-94.

Tretter L, Adam-Vizi V (2005) Alpha-ketoglutarate dehydrogenase: a target and generator of oxidative stress. Philos Trans R Soc Lond B Biol Sci 360: 2335-2345.

Wang W, Andersson M, Lonnroth C, Svanberg E, Lundholm K (2005) Anorexia and cachexia in prostaglandin EP1 and EP3 subtype receptor knockout mice bearing a tumor with high intrinsic PGE2 production and prostaglandin related cachexia. J Exp Clin Canc Res 24: 99-107.

Wang W, Danielsson A, Svanberg E, Lundholm K (2003) Lack of effects by tricyclic antidepressant and serotonin inhibitors on anorexia in MCG 101 tumor-bearing mice with eicosanoid-related cachexia. Nutrition 19: 47-53.
Wang W, Lonnroth C, Svanberg E, Lundholm K (2001) Cytokine and cyclooxygenase-2 protein in brain areas of tumor-bearing mice with prostanoid-related anorexia. Cancer Res 61: 4707-4715.

Wiesinger H, Hamprecht B, Dringen R (1997) Metabolic pathways for glucose in astrocytes. Glia 21: 22-34.

Wu HH, Wilcox GL, McLoon SC (1994) Implantation of AtT-20 or genetically modified AtT-20/hENK cells in mouse spinal cord induced antinociception and opioid tolerance. J Neurosci 14: 4806-4814.

This work is published under the standard license to publish agreement. After 12 months the work will become freely available and the license terms will switch to a Creative Commons AttributionNonCommercial-Share Alike 3.0 Unported License.

Supplementary Information accompanies this paper on British Journal of Cancer website (http://www.nature.com/bjc) 